\title{
NICE guidance on gastroelectrical stimulation for gastroparesis
}

\author{
MARIE-FRANCE KONG
}

\begin{abstract}
Patients with severe diabetic gastroparesis with intractable bouts of nausea and vomiting are often refractory to drug therapy and have poor quality of life with malnutrition, weight loss, poor glycaemic control and frequent hospital admissions. Such patients may benefit from gastroelectrical stimulation (GES). The NICE guidance on GES for gastroparesis in $\mathbf{2 0 0 4}$ did not support its use but since then a considerable amount of new evidence has become available and NICE updated the guidance in May 2014.
\end{abstract}

Br J Diabetes Vasc Dis 2015;15:34-36

Key words: diabetes, gastric emptying, gastroparesis, gastroelectrical stimulation, NICE

\section{Introduction}

In December 2004 NICE issued guidance on gastroelectrical stimulation for gastroparesis which stated:

'Current evidence on the safety and efficacy of gastroelectrical stimulation for gastroparesis does not appear adequate to support the use of this procedure without special arrangements for consent and for audit or research. There is little evidence that the procedure improves gastric emptying. Further research will be useful, and NICE may review the procedure upon publication of further evidence'.1

Since then a considerable amount of new evidence has become available and NICE updated the guidance in May 2014 which now states:

'Current evidence on the efficacy and safety of gastric electrical stimulation for gastroparesis is adequate to support the use of this procedure with normal arrangements for clinical governance, consent and audit. During the consent process, clinicians should inform patients considering gastric electrical stimulation for gastroparesis that some patients do not get any benefit from it. They should also give patients detailed written information

Address for correspondence: Dr Marie-France Kong Consultant Diabetologist, University Hospitals of Leicester NHS Trust, Leicester, LE5 4PW, UK.

Tel: +44 (0)116 2588304

E-mail: marie-france.kong@uhl-tr.nhs.uk

http://dx.doi.org/10.15277/bjdvd.2015.001

\author{
Abbreviations and acronyms \\ GES gastroelectrical stimulation \\ NICE National Institute for Health and Care Excellence
}

about the risk of complications, which can be serious, including the need to remove the device'. ${ }^{2}$

Delayed gastric emptying is an under-recognised complication of diabetes occurring in some $30-50 \%$ of outpatients with longstanding type 1 or type 2 diabetes.3,4 It can be completely asymptomatic, but in those who do experience symptoms, these may be mild, moderate or severe. Gastroparesis tends to follow a relapsing and remitting course, but with increasing severity over time the remissions may get shorter and shorter. Treatment of diabetic gastroparesis includes optimisation of glycaemic control, dietary modifications, prokinetic agents, and antiemetic agents. Although the majority of patients have mild-to-moderate disease that can be managed using these measures, approximately $2 \%$ of patients, particularly the subgroup who have intractable bouts of nausea and vomiting lasting a number of days, are refractory to drug therapy and this can result in inadequate oral intake, malnutrition, weight loss, deranged glycaemic control and can cause poor quality of life with patients needing frequent hospital admissions. Optimal management of these patients presents a difficult challenge for the clinician. If oral intake is not adequate, then enteral nutrition via a jejunostomy feeding tube needs to be considered. Pyloroplasty should be used rarely and partial or complete gastrectomy is regarded as a last resort because of the associated mortality and morbidity. ${ }^{5}$ Although pyloric botulinum toxin injection showed initial promise as a potential treatment option, it is not recommended for patients with gastroparesis based on the outcomes of randomised controlled trials. ${ }^{6}$ In patients with refractory symptoms, particularly nausea and vomiting, there is some evidence to support the use of GES.

\section{Gastroelectrical stimulation}

GES involves implanting a neurostimulating device into the abdomen. The application specifically refers to the use of a device called the Enterra ${ }^{\mathrm{TM}}$ (Medtronic Incorporated, USA) (Figure 1). This device generates a high-frequency (12 cycles per minute), low-energy, short-duration pulse. Electrical stimulation is delivered by two electrodes implanted laparoscopically or during laparotomy into the circular muscle layer along the greater curvature of the stomach, $10 \mathrm{~cm}$ proximal to the pylorus. Leads from the electrodes connect to a neurostimulator, which resembles a cardiac pacemaker that is implanted in the anterior 
Figure 1. The Enterra ${ }^{\mathrm{TM}}$ Device

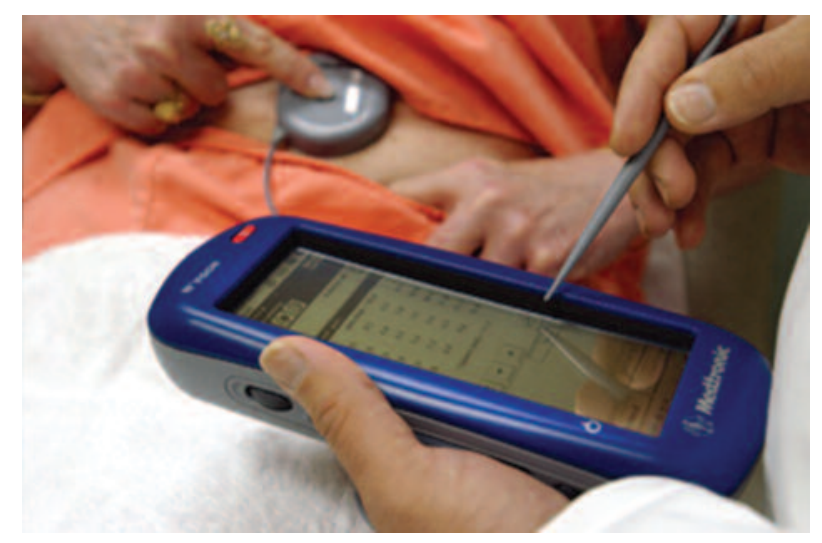

Source http://www.mc.vanderbilt.edu:8080/reporter/index.html?|D=3963

abdominal wall. A wireless remote control allows the settings to be adjusted from outside the body. ${ }^{7}$

The mechanism of action of high-frequency gastric electrical neurostimulation is uncertain, but probably does not relate to stimulation of gastric emptying. Little or no consistent acceleration of solid-phase emptying has been observed in clinical trials of neuro-stimulation. It is hypothesised that high-frequency GES may act on sensory fibres which modulate activity in thoracic spinal neurones that are responsive to gastric distension.

The majority of the published data on GES are of low methodological quality, largely consisting of non-comparative case series reports which include a mixture of prospective and retrospective data collection and patients with and without diabetic gastroparesis. However, two randomised controlled crossover studies have been reported in patients with diabetic gastroparesis. Abell et a/8 studied 33 patients with chronic gastroparesis (17 diabetic and 16 idiopathic). After implantation, patients were randomised in a double-blind, crossover design to stimulation ON or OFF for a 1-month period. After this period of time, all patients were programmed to stimulation ON and evaluated at 6 and 12 months. There was significant benefit with treatment ON versus OFF with the predominant benefit in those with diabetes. Vomiting frequency decreased significantly at 6 and 12 months. Scores for symptom severity and quality of life significantly improved whereas gastric emptying was only moderately accelerated. The study sample size enrolled only about $50 \%$ of patients originally planned and was underpowered. The second controlled study showed no difference between ON and OFF treatment periods after an initial six weeks unblinded on treatment phase. ${ }^{9}$ However, following the ON and OFF treatment periods, all patients had their stimulators turned ON and all had improvements in subjective and objective parameters with chronic stimulation after 12 months of GES, compared with baseline. GES has been reported to enhance nutritional status, reduce the requirement for supplemental feeds, and improve glycaemic control in patients with diabetes.8,10,11 Improvement in gastric emptying has been variable.
An initial meta-analysis ${ }^{11}$ suggested substantial benefits for gastroparesis but identified that, among 13 included studies, 12 lacked controls and only one was blinded and randomised. A more recent meta-analysis on GES showed similar results and identified patients with diabetic gastroparesis as the most responsive to GES, both subjectively and objectively, while the idiopathic gastroparesis and post surgical gastroparesis subgroups were less responsive. ${ }^{12}$ Both meta-analyses and review of the literature indicate that further controlled studies are required to confirm the clinical benefits of high frequency GES. ${ }^{13}$

The neurostimulator has not been documented to reduce fullness, bloating, or acid reflux symptoms. ${ }^{14}$ As a result, it is uncertain if the therapy will be beneficial if these symptoms predominate. Because of the risk of infection after surgery, patients on immunosuppressive therapy may not be optimal candidates for this technology.

GES requires surgery under general anaesthesia. Complications from the device include local infection, lead migration and bowel obstruction, as well as complications related to the surgery which may occur in up to $10 \%$ of patients implanted and the device may require removal. In a case series of 103 patients, 65 of whom had diabetes, treatment failure was reported in $26 \% .{ }^{15}$ In patients with diabetes a non-responder rate of $10 \%$ has been reported. ${ }^{16}$ Average battery life is seven years to a likely maximum of 12 years. GES is a costly treatment, estimated at about $£ 16,000$ to $£ 18,000$ per patient. Additional costs may be incurred if complications arise. There are potential reductions in healthcare costs such as reduced hospital admissions and reduction/withdrawal from enteral and parenteral nutrition. Reductions in use of medication for gastroparesis are unlikely to lead to important savings. Patient numbers have been estimated at one or two patients per Clinical Commissioning Group per annum.

\section{Conclusions}

There is no consensus or societal guideline on the selection of patients (e.g., failed therapeutic trials, or level of nutritional compromise) for the use of GES. Patients with severe nausea and vomiting (occurring on average at least once daily), which have proven refractory to aggressive antiemetic and prokinetic drug therapy for at least one year in duration, may be candidates for GES. Patients with nausea and vomiting and those without narcotic dependence prior to placement of the stimulator have a more favourable clinical response than those with bloating or abdominal pain.

NICE recommends that patient selection and follow-up should be done in specialist gastroenterology units with expertise in gastrointestinal motility disorders and the procedure should only be performed by surgeons working in these units. Centres that currently offer GES are Broomfield Hospital in Essex, Royal Free Hospital and University College London Hospital, Leeds, Aintree, Russells Hall Hospital in Dudley, West Midlands, Glasgow and Aberdeen. To date, 350 patients have received an EnterraTM implant in the UK (personal communication, Medtronic, August 2014). The centre in Broomfield Hospital has 


\section{Key messages}

- Gastroparesis is a much under-recognised complication of diabetes mellitus; it can be asymptomatic, mild, moderate or severe and may affect $30-50 \%$ of patients with long-standing diabetes

- GES has been reported to enhance nutritional status, reduce the requirement for supplemental feeds and improve glycaemic control in patients with diabetes

- NICE recommends that patient selection and follow-up should be done in specialist gastroenterology units with expertise in gastrointestinal motility disorders and the procedure should only be performed by surgeons working in these units

now done 100 implants and reports a low complication rate and following the procedure 25 out of 32 patients have stopped enteral and parenteral feeding (personal communication, S Kadirkamanathan, Broomfield Hospital, September 2014). A centralised database of statistical data on GES submitted by all the specialist centres would be beneficial to both clinicians and patients in providing outcome data which will help clarify the characteristics of those who may potentially have the best clinical response.

\section{Conflict of interest None. Funding None.}

\section{References}

1. National Institute for Health and Care Excellence. Gastroelectrical stimulation for gastroparesis: Interventional procedure guidance 103. December 2004. http://www. nice.org.uk/Guidance/ipg103

2. National Institute for Health and Care Excellence. Gastroelectrical stimulation for gastroparesis: Interventional procedure guidance 489. May 2014. http://www.nice.org.uk/Guidance/IPG489
3. Horowitz M, Harding PE, Maddox A, et al. Gastric and oesophageal emptying in insulin dependent diabetes mellitus. J Gastroenterol Hepatol 1986;19:97-113. http://dx.doi.org/10.1111/J.1440-1746.1986.tb00104.x

4. Horowitz M, Harding PE, Maddox AF, et al. Gastric and oesophageal emptying in patients with type 2 (non-insulin-dependent) diabetes mellitus. Diabetologia 1989;19:151-9. http://dx.doi.org/10.1007/BF00265086

5. Eckhauser FE, Conrad M, Knol JA, et al. Safety and long-term durability of completion gastrectomy in 81 patients with postsurgical gastroparesis syndrome. Am Surg 1998;64:711-16.

6. Bai $Y, X u M J$, Yang $X$, et al. A systematic review of intrapyloric botulinum toxin injection for gastroparesis. Digestion 2010;81:27-34. http://dx.doi.org/10.1159/000235917

7. de Csepel J, Goldfarb B, Shapsis A, et al. Electrical stimulation for gastroparesis. Gastric motility restored. Surg Endosc 2006;20:302-06. http://dx.doi.org/10.1007/s00464-005-0119-4

8. Abell T, McCallum R, Hocking M, et al. Gastric electrical stimulation for medically refractory gastroparesis. Gastroenterology 2003;125:421-8. http://dx.doi.org/10.1016/S0016-5085(03)00878-3

9. McCallum RW, Snape W, Brody F, et al. Gastric electrical stimulation with Enterra therapy improves symptoms from diabetic gastroparesis in a prospective study. Clin Gastroenterol Hepatol 2010;8:947-54. http://dx.doi.org/10.1016/j.cgh.2010.05.020

10. McCallum RW, Lin Z, Forster J, et al. Gastric electrical stimulation improves outcomes of patients with gastroparesis for up to 10 years. Clin Gastroenterol Hepato/ 2011;9:314-19. http://dx. doi.org/10.1016/j.cgh.2010.12.013

11. O' Grady G, Egbuji JU, Du P, et al. High-frequency gastric electrical stimulation for the treatment of gastroparesis: a meta-analysis. World I Surg 2009;33:1693-701. http://dx.doi.org/10.1007/s00268-009-0096-1

12. Chu H, Lin Z, Zhong L, et al. A meta-analysis: the treatment of highfrequency gastric electrical stimulation for gastroparesis. I Gastroenterol Hepatol 2012;27:1017-26. http://dx.doi.org/10.1111/j.1440-1746.2011. 06999.x

13. Camilleri M, Parkman HP, Shafi MA, et al. Clinical guideline: management of gastroparesis. Am J Gastroenterol 2013;108:18-37. http://dx.doi.org/10.1038/ajg.2012.373

14. Maranki JL, Lytes V, Meilahn JE, et al. Predictive factors for clinical improvement with Enterra gastric electric stimulation treatment for refractory gastroparesis. Dig Dis Sci 2008;53:2072-8. http://dx.doi.org/10.1007/s10620-007-0124-7

15. Zehetner J, Ravari F, Ayazi S et al. Minimally invasive surgical approach for the treatment of gastroparesis. Surg Endosc 2013;27:61-6. http://dx.doi.org/10.1007/s00464-012-2407-0

16. McCallum RW, Lin Z, Sarosiek I, et al. Predictors of symptom non-responders to high-frequency gastric electrical stimulation for refractory gastroparesis. Neurogastroenterol Motil 2006;18:480-1. http://dx.doi.org/10.1111/j.1365-2982.2006.00789_3.x

\section{Erratum to 'Consensus recommendations for the use of Ambulatory Glucose Profile in clinical practice'}

(Br J Diabetes Vasc Dis 2014;14(4):153-157. http://dx.doi.org/10.15277/bjdvd.2014.046)

\section{STEPHAN MATTHAEI, RAMIRO ANTUÑA DEALAIZ, EMANUELE BOSI, MARK EVANS, NEL GEELHOED-DUIJVESTIJN, MICHAEL JOUBERT}

We regret that an error occurred on page 154. Figure 1 had incorrect labels applied as the 10th to 90th percentile is included twice, whereas one of the labels should say the 25th to 75th percentile. The correct figure is shown opposite.

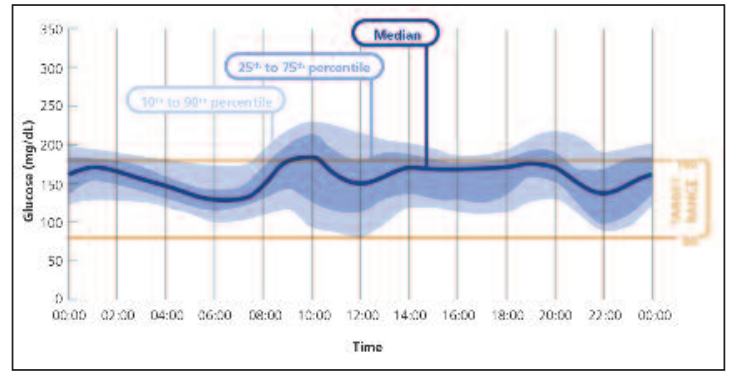

